\title{
Power System Harmonics
}

\author{
Olutayo Ogunyemi \\ School of Science and Engineering, Atlantic International University, Honolulu, HI.
}

The research is financed by self.

\begin{abstract}
Good power quality is essential in electrical power network. Power quality is not limited to availability of supply but also include steady frequency value and voltage magnitude and smooth waveform characteristics of the supply (Ogheneovo Johnson, 2016). The present situation of poor power quality in industrial and commercials sites, especially harmonics had created some form of attention to one of the power problems in the world; harmonics. This situation is as a result of the growth in the use of non-linear loads. The increase in the use of non-linear load had brought about the tight recommendations of IEEE standard 519 especially in the industrial and commercial sector (Robert G.Ellis, 2011).In practical terms, power quality can be defined as the rate at which the essential power parameters magnitude which are voltage, frequency and current deviates from the nominal values and can cause damage to the power infrastructure or equipment in use. In reality, there are about nine prominent power problems facing power system. These power issues are under voltage, over voltage, power sag, power surge, frequency distortion, line noise, power outage, switching transient and harmonic distortion. Power quality is said to be poor when any of the power problems is manifested within the power system.Mostly, harmonics occur as a result of alteration of the normal waveform which is generally transmitted by non-linear loads. This paper will dwell more on harmonics and its consequences in power system. Non-linear loads that cause situation of harmonics will also be reviewed in the course of this assignment.
\end{abstract}

Keywords: Total Harmonic Distortion (THD), Multipliers, Non-linear loads, Total Demand Distortion (TDD).

DOI: $10.7176 / \mathrm{JETP} / 9-3-02$

Publication date:March $31^{\text {st }} 2019$

\section{Introduction}

Harmonics in three phase system power system was studied by Steinmetz in 1960 where concerns were raised on the behavior of third harmonic current which were produced from the effect of saturated iron within transformers core as well as electric machines. He was able to resolve the effect of the third level harmonics by proposing a delta connection in three phase power system which was able to block the effects of the third harmonics current (Abdelaziz, Mekhamer and Ismael, 2012).

Thereafter, rural electrification and telephone service came into existence and both the power infrastructure and the telephone circuits were mostly installed alongside with one another. Consequently, magnetizing current from transformers generated harmonic current and this created an inductive interference with the telephone circuits. Research was thereafter carried out with the purpose of eliminating the problem caused by this innovation. The interference produced is so enormous that the essence of voice communication seems defeated. Upon the completion of the research and study of the problem, a resolution emerged and the problem was addressed by filtering and placing design limits on transformer magnetizing currents (Abdelaziz, Mekhamer and Ismael, 2012)

Now that twisted pair, buried cables and fibre optics had replaced the open-wire telephone circuits and more or less, the installation of rural electrification and telephone systems are no longer placed on the same right-ofway, it is logically expected that situation of harmonics is not experienced but they still persist but not on regular basis as previously experienced (Grady, 2012).

In recent times, the usual sources of harmonics are loads that emanate from power electronics. Examples of such loads are switching power supplies, adjustable speed drives (ASD), uninterruptible power supply (UPS) and static VAR compensators. These load types have active components like the power transistors, silicon controlled rectifiers (SCR), diodes and other semiconductor electronic switches that interferes with the sinusoidal waveforms to control the power or possibly transforms the AC power network to DC power thereby creating non-sinusoidal currents from the main (Abdelaziz, Mekhamer and Ismael, 2012)

The submissions of Fourier had been of great value and had contributed to the analysis of the non-sinusoidal waveform by allowing any periodic function to be used or described in a series of sinusoidal and co-sinusoidal functions(Grady, 2012). For instance, if we are applying a fundamental frequency of $50 \mathrm{~Hz}$, then the second harmonics will be $100 \mathrm{~Hz}$, and the third, $150 \mathrm{~Hz}$, and so on. The respective harmonics can sum up to reproduce the original waveform and the highest harmonics of interest in power system is usually the twenty-fifth and this is in the low audible range (Soni and Soni, 2014)

Over twenty years now, there had been an appreciable and noticeable effort geared towards the analysis of power system harmonics. In this analysis, procedures for simulation methods and component models had been put in place such that the study of harmonics is becoming an important component of power system analysis and 
design (Durdhavale, 2016). Based on this and the knowledge of digital computers, computer simulation is now the preferred method to conduct harmonic analysis. Computer modeling for power systems for harmonic analysis and computer simulation of harmonic propagation in power systems are the two main aspects of harmonic analysis [7].

In theoretical terms, an ideal power system produces a perfect sinusoidal voltage signal at the load side but such theory is difficult to achieve practically. A distortion in power system is said to have occurred when there is a deviation from the perfect sinusoidal waveform. When this is experienced, then harmonic distortion has occurred. When electrical equipment is working in good and normal condition or when it is not loaded, only odd harmonics are produced but when transient conditions or possible equipment mal-function exist, then the system will generate even harmonics.

The present situation of poor power quality in industrial and commercials sites, especially harmonics had created some form of attention to one of the power problems in the world; harmonics. This situation is as a result of the growth in the use of non-linear loads. The increase in the use of non-linear load had brought about the tight recommendations of IEEE standard 519 especially in the industrial and commercial sector (Robert G.Ellis, 2011). Harmonics in power system should not be treated with levity as they are of great concern in the power sector. Harmonics usually affects power infrastructure and the equipment therein and most times causes a down time in operations as people may think that the problem at that point is load related. Harmonics in power system lead to situation of over-current and over-heating leaving an impression of a possible situation of overload in the power system.

\section{Discussion}

\subsection{Fundamentals of Harmonics}

Harmonics can also be known in power system as distorted waveforms and the classification of these waveforms fall in two categories; the voltage and current harmonics. There two concept also used to describe harmonics; they are the orders of harmonics and symmetrical components. Generally, harmonic component is illustrated in the equation below:

$f_{h}=\frac{f_{n}}{f_{1}} \times 100$

Where

$f_{n}=$ current amplitude of nth order harmonic

$\mathrm{f}_{1}=$ fundamental current amplitude.

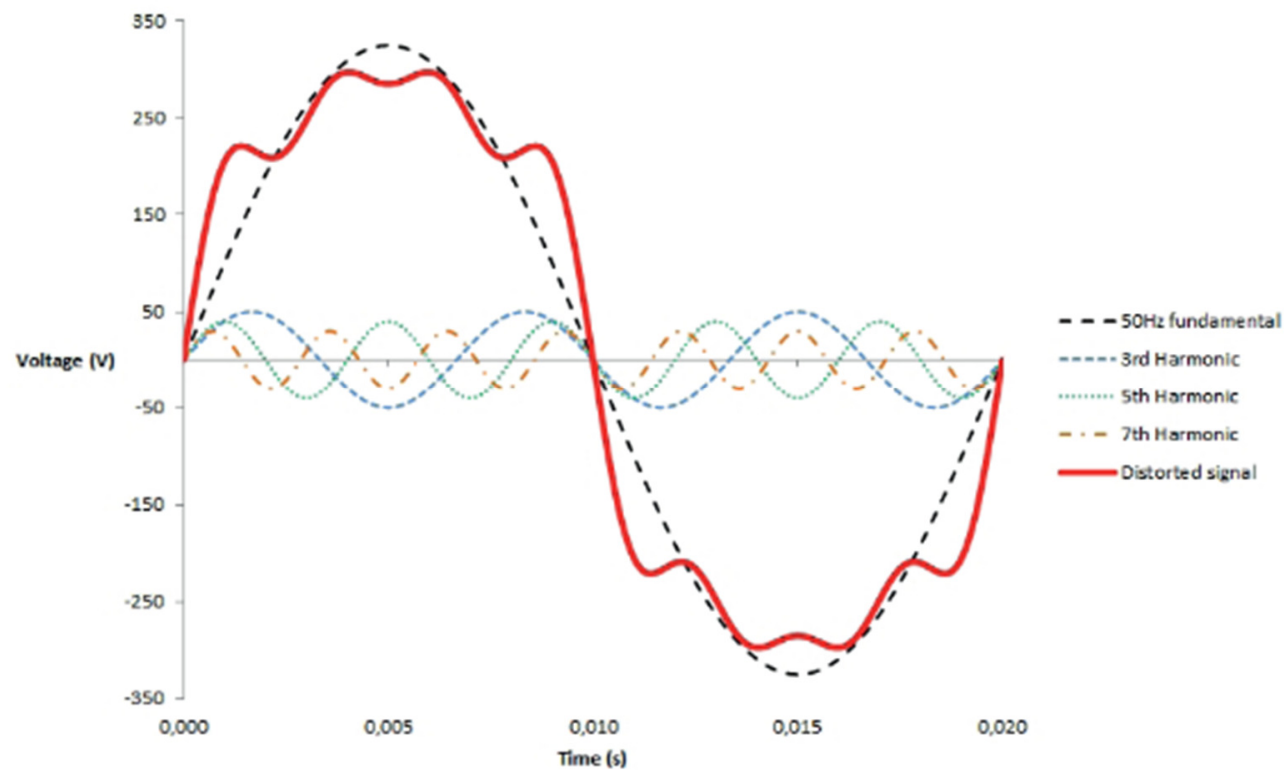

Figure 1: Decomposition example of a complex distorted signal, as addition of $50 \mathrm{~Hz}$

Fundamental and $3 \mathrm{rd}, 5^{\text {th }}$ and 7 thharmonics $(150 \mathrm{~Hz}, 250 \mathrm{~Hz}, 350 \mathrm{~Hz}$ respectively) (Pinyol, 2015)

There is harmonics in a power network if the component of a waveform occurs at an integer multiple of the fundamental frequency. In the description of harmonic orders, the odd order harmonics and the even order harmonics are the common nomenclatures known for classification. However, there is a third classification, the triplet harmonic which is not much known. The table 1 below shows the classification of harmonics in terms of the "order". Presently, the characteristics of the harmonic component in the power system are the odd harmonics and the odd harmonics are also represented by the waveform that symmetrical to the time axis. Even harmonics are only produced from waveforms that are not symmetrical to the time axis (Durdhavale, 2016). 
Table 1: Harmonics Order (Durdhavale, 2016)

\begin{tabular}{|l|l|}
\hline & Harmonic Orders \\
\hline Odd & $5^{\text {th }}, 7^{\text {th }}, 11^{\text {th }}, 13^{\text {th }}, 17^{\text {th }}$ \\
\hline Even & $2^{\text {nd }}, 4^{\text {th }}, 6^{\text {th }}, 8^{\text {th }}, 10^{\text {th }}, 12^{\text {th }}$ \\
\hline Triplen & $3^{\text {rd }}, 9^{\text {th }}, 15^{\text {th }}, 21^{\text {st }}$ \\
\hline
\end{tabular}

There are three broad categories in which harmonics can be placed and this is expressed in terms of sequence. The positive sequence harmonics, negative sequence harmonics and the zero sequence harmonics. The positive sequence harmonics are made up of the $4^{\text {th }}, 7^{\text {th }}, 10^{\text {th }}, 13^{\text {th }}$ and $19^{\text {th }}, \ldots .3 \mathrm{k}+1$ order harmonics and the negative sequence harmonics are consist of the $2^{\text {nd }}, 5^{\text {th }}, 8^{\text {th }}, 11^{\text {th }} 14^{\text {th }}$, and $17^{\text {th }} \ldots .2 \mathrm{k}+1$ order harmonics while the $3 \mathrm{rd}, 6^{\text {th }}$ $9^{\text {th }}, 12^{\text {th }}$ and $15^{\text {th }} 3 \mathrm{k}+3$ order harmonics are attributed to the zero sequence harmonics. Where $\mathrm{k}$ ranges from 0 , 1,2,3, etc. See Table 2 below for illustration (Kamenka, 2014). In a system where three phase four wire is the wiring arrangement, the zero sequence harmonics system the zero sequence harmonics drifts through the neutral connection and causes an overheating of the conductor (Dash et al., 2014).

Table 2: Symmetrical Component of Harmonics (Kamenka, 2014)

\begin{tabular}{lrrr}
$\begin{array}{l}\text { Symmetrical } \\
\text { components }\end{array}$ & $\begin{array}{r}\text { Positive sequence } \\
(+)\end{array}$ & $\begin{array}{r}\text { Negative sequence } \\
(-)\end{array}$ & $\begin{array}{r}\text { Zero sequence } \\
\text { (homopolar) }\end{array}$ \\
\hline & 1 & 2 & 3 \\
\cline { 2 - 4 } Harmonic order & 4 & 5 & 6 \\
\cline { 2 - 4 } & 7 & 8 & 9 \\
\cline { 2 - 4 } & 10 & 11 & $\ldots$ \\
\cline { 2 - 4 } & $\ldots$ & $3 \mathrm{k}+2$ & $3 \mathrm{k}+3$ \\
\hline & $3 \mathrm{k}+1$ & $\mathrm{k}=0,1,2,3, \ldots$
\end{tabular}

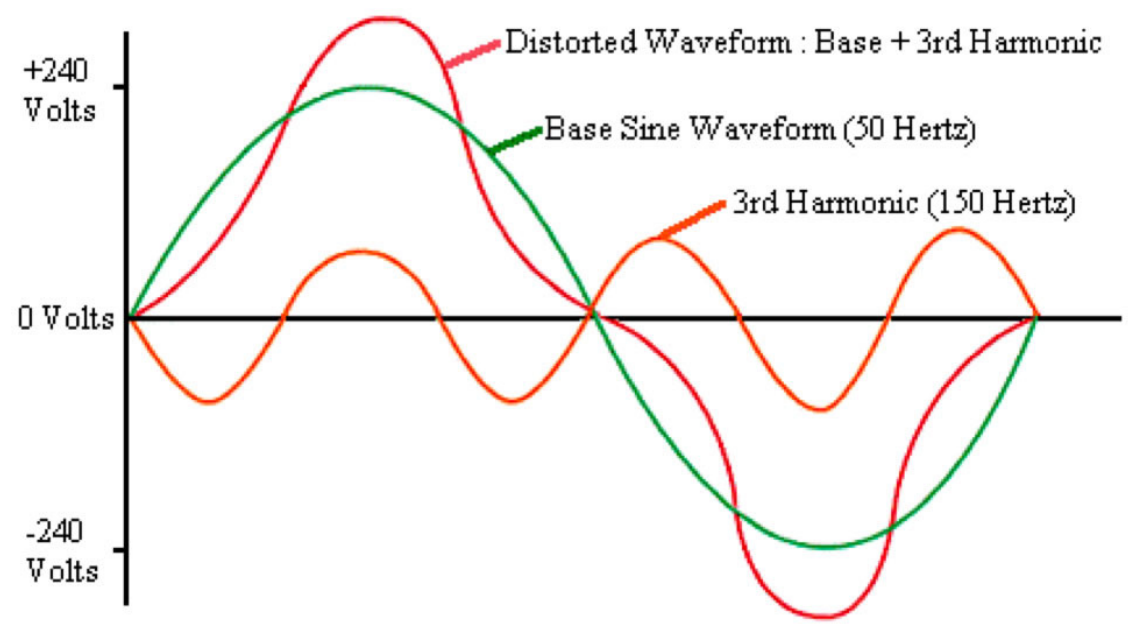

Figure 2: Harmonic Distortion for a 50HZ Power System [11]

Fourier postulated a theory and in his theory, we were able to depict that any The Fourier theory tells us that any repetitive waveform is defined as the sum of the sinusoidal waveforms which are integer factor of the fundamental frequency. With the consideration of a steady state waveform with characteristics of equal positive and negative half cycles, the Fourier series can be expressed in equation 2 as shown below (Dash et al., 2014)

$f(t)=\sum_{n=1}^{\infty} A_{n} \cdot \operatorname{Sin}\left(\frac{n \pi t}{T}\right)$

Where

$\mathrm{f}(\mathrm{t})=$ the time domain function.

$\mathrm{n}=$ the harmonic number (putting in consideration odd values only).

$\mathrm{A}_{\mathrm{n}}=$ the amplitude of the nth harmonic component.

$\mathrm{T}=$ the period or length of one cycle in seconds.

It is worthy of note that harmonics being a steady state phenomenon will repeat every $50 \mathrm{~Hz}$ or $60 \mathrm{HZ}$ cycle, depending on the power system in place. Spikes, dips and other forms of transient do not imply a situation of harmonics and should not be confused with harmonic condition (Robert G.Ellis, 2011). 


\subsection{Power Quality Indices under Harmonics}

\section{i. $\quad 2.2 .1$ Total Harmonic Distortion}

The factor that is mostly used to determine the deviation of distorted waveforms from a sine wave is called Total Harmonics Distortion (THD) and this is described in relation with the degree of distortions in both the waveforms of the current and voltage in the power network. The calculation of distortion in the voltage and current is given in equation 3 below. As it may be seen in other publications or books, another term that can be used to describe the Total Harmonic Distortion is known as the Distortion Factor (DF) (Robert G.Ellis, 2011).

$$
T H D(\%)=\sqrt{I D_{1}^{2}+I D_{2}^{2}+\cdots \cdot I D_{n}^{2}}
$$

Where

$\mathrm{ID}_{\mathrm{n}}$ represent the magnitude of the nth harmonic as a percentage of the fundamental (individual distortion).

Grady, in 2012 [4] defined THD as the ratio of the root mean square value (rms) of the harmonic above fundamental to the rms value of the fundamental. Marcuello, Arcega, Plaza, \& Ibáñez, in 2011[12] termed THD as the rms value as the proportion of of all harmonic components together to the rms amplitude of the fundamental harmonics. In a white paper by Eaton in 2017 (Eaton, 2017), THD was described as the fraction of the total power of all harmonic components to the power of the fundamental frequency. Similar definition was also given by Durdhavale, in 2016.

Total Harmonic Current (THC)

The summations of current orders 2 to 40 are the cause of distorted waveforms leading to Total Harmonic Current. The value of the Total Current Harmonics (THC) is basis for the installation of active filters. Mathematically, THC can be illustrated as in equation 4 (Durdhavale, 2016).

$T H C=\sqrt{\sum_{n=2}^{n=40} I h^{2}}$

Where Ih is the harmonic current of the nth order.

Total Harmonic Distortion Current (THDi)

The Total Harmonic Distortion Current (THDi) describes the magnitude of distortion present in a waveform It is derived from the fraction of the Total Harmonic Current (THC) and the fundamental current. It is expressed mathematically as shown in equation 5 below (Durdhavale, 2016)

$T H D_{i}=\sum_{n=2}^{n=40} \frac{I h^{2}}{I 1}=\frac{T H C}{I 1}$

Where I1 is the fundamental current

Total Harmonic Distortion of Voltage (THDv)

This is a representation of the total value of the voltage distortion in a given waveform. It can be derived from the ratio of the harmonic voltage to the non-harmonic or fundamental voltage (Pinyol, 2015). THD can $_{\mathrm{v}}$ be expressed as:

$T H D_{v}=\sqrt{\sum_{n=2}^{n=40} \frac{V n^{2}}{V 1} \times 100}$

Where $\mathrm{Vn}=$ voltage amplitude of the $\mathrm{nth}$ order harmonic,

$\mathrm{V} 1$ = fundamental or non-harmonic voltage amplitude.

Total Demand Distortion (TDD)

Total Demand Distortion is commonly used to describe harmonics in the North America region. It is however defined as the division of the harmonic current by the full load fundamental current. The full load current is also the total non-harmonic current demanded by all load at peak time. Mathematically, it can be written as shown in equation 7 below.

$T D D=\sum_{n=2}^{n=40} \frac{I n^{2}}{I l}=\frac{T H C}{I l}$

Where In is termed as the current amplitude of the nth order harmonic,

IL is the total load current demand by the system.

The definitions of THD and TDD are alike only that THD compared the harmonic content with measured fundamental current while TDD evaluates its distortion with the maximum demand current. Considering the definitions of the fundamental current (I1) and the maximum demand current (IL), the value of IL is greater than I1 for harmonic measurement purpose, hence the value of TDD and the percent of IL will tend to be lower than THD and its corresponding percent of I1 measurement. The determination of the values of THD and TDD is relevant as it assist in determining the accurate value of harmonic generated by a facility's power network during the time where light loads are being used. (IEEE Recommended Practices and Requirements for Harmonic Control in Electric Power Systems, 1992)

Partial Weighted Harmonic Distortion (PWHD)

PWHD can be expressed as the ratio of the voltage or current within a selected group of harmonics higher order (say $14^{\text {th }}$ order to $40^{\text {th }}$ order) to the fundamental values of the current or voltage, as the case may be. PWHD equations for current and voltage can be given as shown in equation 8 and 9 below (Durdhavale, 2016) 
PWHD, $I=\sum_{n=14}^{n=40} \frac{I n^{2}}{I 1} \times 100$

Or

$P W H D, V=\sum_{n=14}^{n=40} \frac{V n^{2}}{V 1} \times 100$

Where I1 can be expressed as the fundamental current amplitude, and V1, the fundamental voltage amplitude.

\subsection{Sources and Causes of Harmonics Distortion}

Harmonics come into play as a result of non-linear loads in the power network. In recent times, enhanced power semiconductor technology coupled with power electronics devices are now used in various applications in the field of electrical and electronics engineering. These applications are in the classification on non-linear loads and thus the devices demand current with harmonic content and reactive power from the AC component of the power network (Panda et al., 2013).

For better understanding of the sources and caused of harmonic distortion, it is important to explain briefly the term "non-linear load". We can say that a load is non-linear when the current demand from such load does is not even with the connected sinusoidal voltage. This implies that the Ohm's law is not applicable in describing the Voltage-Current relationship as the resistance is not a constant value any longer and there will be a change in current value with each produced sinewave of the applied voltage waveform. This situation causes several positive and negative pulses. The varying current values are termed to be non-linear and they produce frequency components that are manifolds of the frequency of the power system. Besides the fact that the non-linear current produces multiples of the frequency of the power system, they also form a network with the impedance of the electrical power supply to form voltage distortion that can affect the power network and the load on it (Kamenka, 2014).

The simplest network that can be used as an illustration for a non-linear load is a diode-rectifier in its various applications such as the half-wave diode rectification, full wave diode rectification in both single phase and three phase network (Pinyol, 2015). Table 3 below shows the various classification of non-linear load responsible for the generation of harmonic distortion in a power network.

Table 3: Non-Linear Loads (Kamenka, 2014)

\begin{tabular}{ll} 
Power electronics & Arc devices \\
\hline Variable speed drives & Welding machines \\
\hline Switched mode power supplies & fluorescent light ballasts \\
\hline Battery chargers & ARC furnace \\
\hline IT equipment & \\
\hline UPS & \\
\hline
\end{tabular}

Prior to now, equipment with magnetic iron cores like electric motors, transformers and generators were known to be predominant in the cause of harmonic distortion in power network. Likewise, the arc furnaces and the arc welder's equipment also cause harmonic distortion in power network. In recent times, where energy efficiency is crucial, there had been some introduction of power electronic equipment to enhance energy efficiency utilization and these equipment had contributed to the most serious source of harmonics within a power network in industrial and commercial facilities (Kamenka, 2014).

ii. $\quad$ 2.3.1 Transformers

The magnetization curve explains the correlation between the input or primary voltage and current of a transformer. A transformer is working in normal condition does not generate any form of harmonic distortion unless the transformer is in a core saturation condition. At this condition, the harmonic distortion increases appreciably with the odd orders of harmonics, the third order being dominant. This kind of condition is show cased when the transformer is operating in an overload condition, especially during peak periods or when the transformer is subjected to an overvoltage condition, especially at situation of low power demand or possible switching of large reactive power load. This harmonic content is manifested in the magnetization curve of the transformer as in figure 3 below. When the transformer is working in normal condition, a little increase in the voltage usually result in a little rise in the magnetization current. Similarly, when an overvoltage condition exist, that is when the voltage is above the nominal voltage, then a small increase in voltage will result in having a large increase in the magnetization current (Kamenka, 2014). 


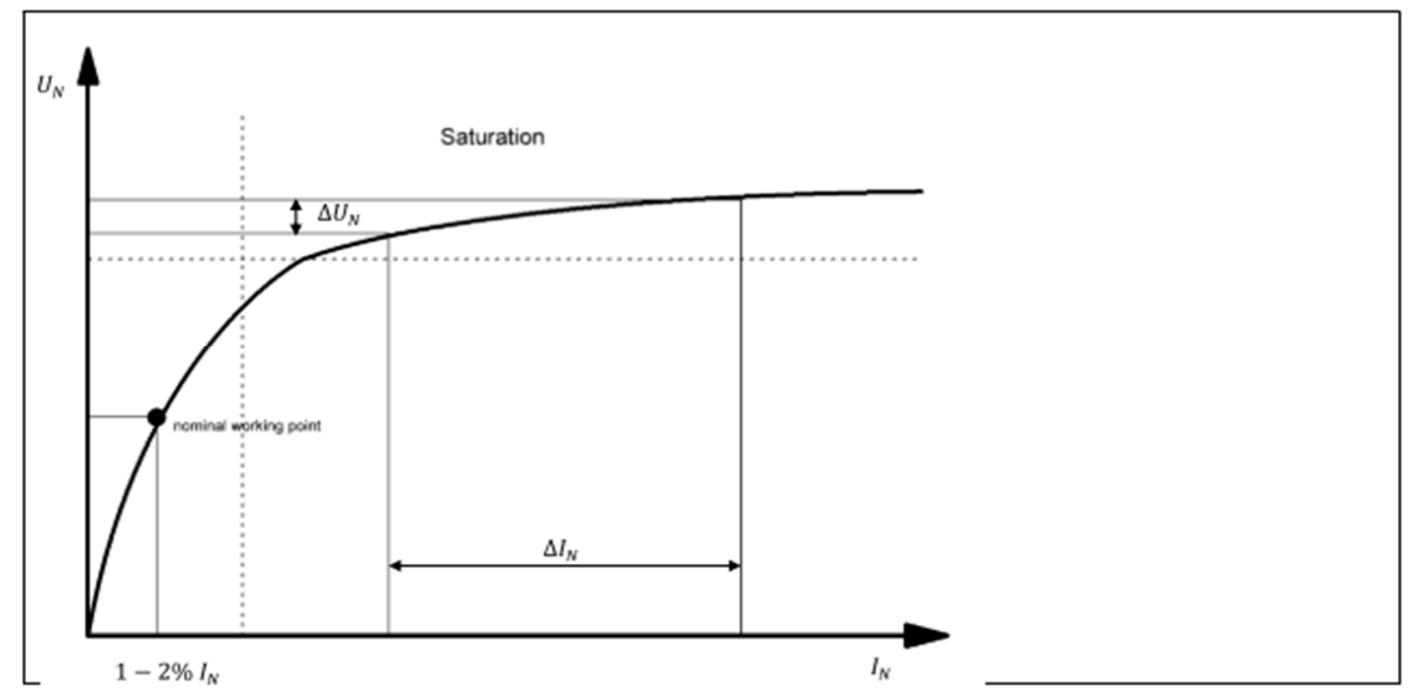

Figure 3: Transformer Magnetization Curve (Kamenka, 2014)

iii. $\quad$ 2.3.2 Rotating Machines

Generators and Motors are examples of rotating machines and they also produce magnetizing field like transformer, hence they are capable of producing harmonics in power network. Though the harmonic content of produced as a result of the magnetization curve of motors is much more linear when compared to that produce by a transformer, thus, the harmonic content is not disturbing, however, the higher capacity motors have capacity of generating high harmonic content. On the other hand, generators produce observable voltage harmonics following the unpractical nature of the spatial distribution of the stator winding. The voltage harmonics produced from a generator are the $3^{\text {rd }}$ order harmonics which in turn causes creates a $3^{\text {rd }}$ order current harmonic in the power network (Durdhavale, 2016).

iv. $\quad$ 2.3.3 Arc Furnaces and Arc Welders

Arc furnaces and arc welders are high power consuming equipment that also produce corresponding high level of harmonic distortion in a power network. Arc furnaces are applicable in air refining, refining and melting applications and these phases produces different levels and gradients of harmonics. The random variation of the arc produces a combination of ignition delays and voltage changes and this situation creates some sort of harmonic spectrum with odd and even multiples of fundamental frequency. These frequencies changes intermittently with various swift levels of rise and falls (Suresh and Babu, 2015)

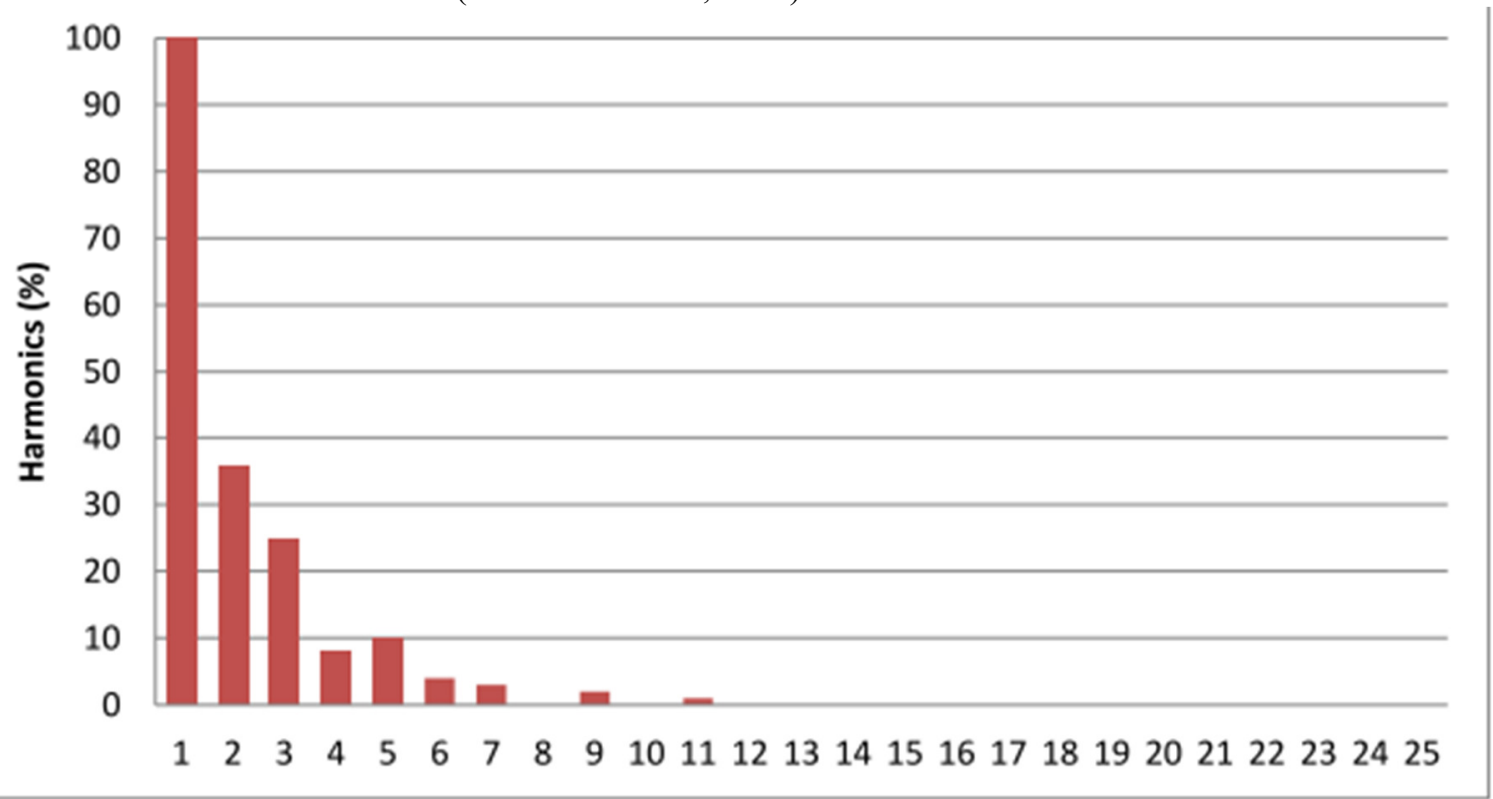

Figure 4: Harmonic Current Spectrum in Arc Furnace (Kamenka, 2014).

v. 2.3.4 Switched Mode Power Supplies (SMPS)

Most of the electronic devices of today are embedded with Switched Mode Power Supplies and the name is on the basis of the switching and conversion of unregulated DC input voltage to a regulated DC output voltage. Based on 
the SMPS principle of operation where rectifying and filtering at various stages is involved, this result in the demand of pulses of current instead of continuous current. This pulse is made of high content of harmonics of the third order and even higher orders. A typical waveform and the harmonic spectrum is shown in figure 5 below (Durdhavale, 2016)

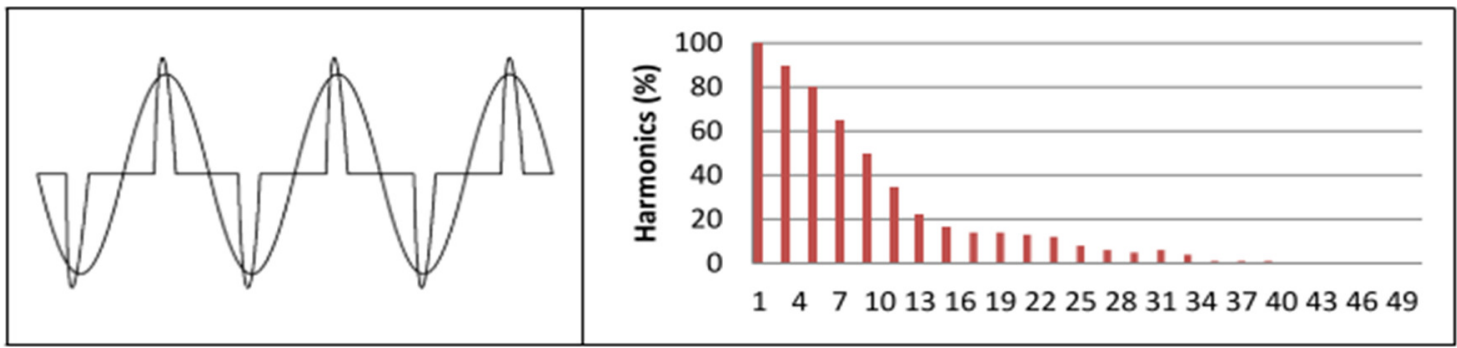

Figure 5: Waveform and Harmonic Current Spectrum of SMPS (Kamenka, 2014)

vi. $\quad$ 2.3.5 Variable Frequency Drives

Variable frequency drives are applicable to equipment that uses the technology of static converters in a three-phase bridge system. We can term the bridge as six-pulse bridge or B6 bridge. This same technology is also applied in UPS application as well as inverter applications, basically AC to DC converters.

The term B6 as earlier mentioned came to being from the trend of pulse generated, six voltage pulses per cycle which corresponds to the production of one pulse in a half cycle per phase. The harmonic spectrum in this case is attributed to the magnitude of pulses of the variable frequency drives. The current harmonics that emanates from a B6-bridge is in the $6 n \pm 1$ orders which implies that we can either have orders in the form of $5^{\text {th }}$ and $7^{\text {th }}, 11^{\text {th }}$ and13th, $17^{\text {th }}$ and $19^{\text {th }}$, just to mention a few. As the harmonic spectrum is dependent on the number of pulse, so the harmonic spectrum will be different if 12 or 18 pulse converter is applied for the application. See table for more information. Figures 6 illustrate how the waveform looks like; its resulting harmonic spectrum is also included.

Table 4: Pulse and Harmonic Spectra in a Variable Speed Drive (Kamenka, 2014)

Number of pulses

Formula

Possible harmonics

\begin{tabular}{lrr}
\hline $\mathbf{n}$ & $h=(n * p) \pm 1$ & \\
\hline $\mathbf{2}$ & $\mathrm{h}=(n * 2) \pm 1$ & $2,3,4,5,6,7, \ldots$ (all) \\
\hline $\mathbf{6}$ & $\mathrm{h}=(n * 6) \pm 1$ & $5,7,11,13,17,19, \ldots$ (pairs) \\
\hline $\mathbf{1 2}$ & $\mathrm{h}=(n * 12) \pm 1$ & $11,13,23,25,35,37, \ldots$ (pairs) \\
\hline $\mathbf{1 8}$ & $\mathrm{h}=(n * 18) \pm 1$ & $17,19,35,37, \ldots$ (pairs) \\
\hline $\mathbf{2 4}$ & $\mathrm{h}=(n * 24) \pm 1$ & $23,25,47,49, \ldots$ (pairs) \\
\hline
\end{tabular}

p...number of pulses, n...integer number $(1,2,3 . .$.$) , h...harmonic order$

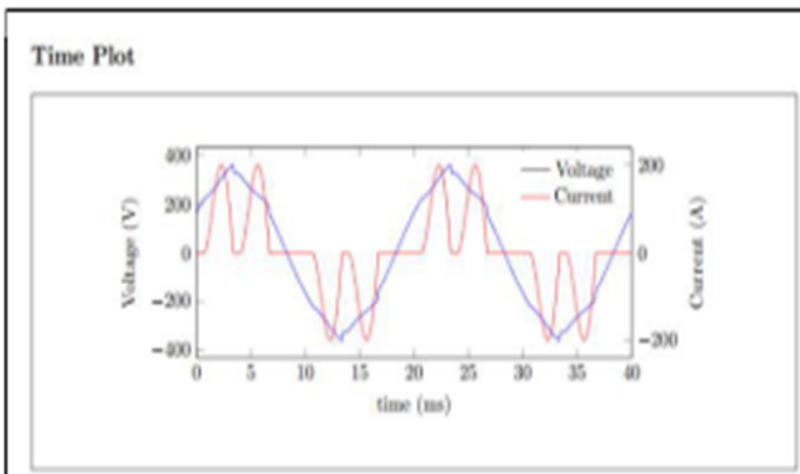

FFT Plot

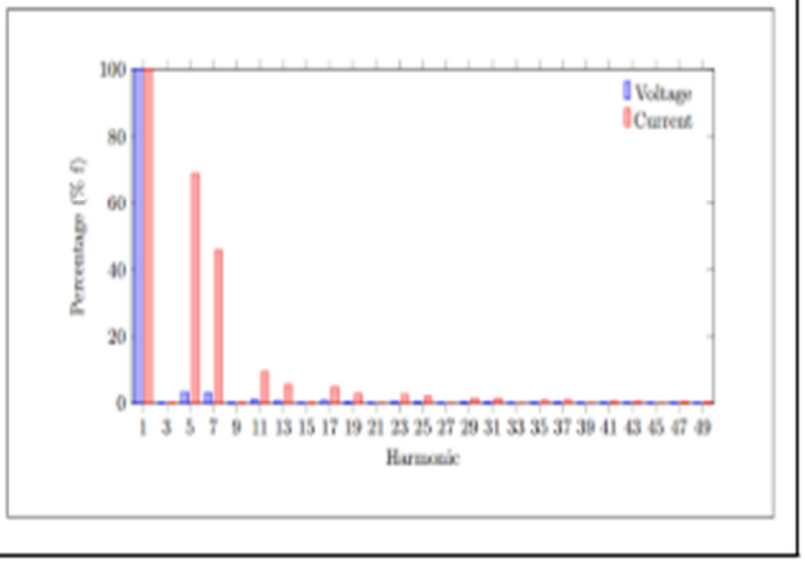

Figure 6: Waveform and Harmonic Spectrum of a B-6 Variable Speed Drive (Kamenka, 2014)

\subsection{Effects of Harmonics Distortion}

Implications of harmonics within the power network can be categorized in terms of their duration, for instance, it 
could either be short term or long term. The failures or malfunctions of equipment or devices subjected to harmonic distortion can be categorized as short term effects while long terms effects can be linked with the thermal behavior of the devices or equipment. Harmonic situation lead to scenarios of thermal build-up or temperature rise in equipment and electrical network. When there are situations of increased temperature of electric or electronic devices, cables, motors arc, then besides the effect of higher losses, the equipment or system life becomes reduced (Suresh and Babu, 2015).

\section{vii. 2.4.1 Power Factor}

When there are situations of harmonic distortion in a power network, the power factor of the network gets affected following a higher demand in the level of current. The power factor becomes exceedingly low if there is an increase in the phase shift between the voltage and current, certainly with a situation of current harmonics within the system. Power factor can simply be explained in terms of the relationship between the active power and the apparent power. It can be defined as the ratio of the true power (in watts) to the apparent power (in VA). It determines or measures the efficiency of the energy used by a load in a power network. Power system with a high power factor demands less current when compared to that with a low power factor under the same power conditions. This implies that systems with higher power factor are more efficient than those of lower power factor. The effects of harmonic distortion which is predominant in non-linear load tend to cause a situation of bad power factor, thus lowering the efficiency of the system (Kamenka, 2014).

\section{viii. 2.4.2 Phase and Neutral Conductors}

Practically, three phase system are such that they possess phase angles and in an ideal system, the phase voltages are displaced by $120^{\circ}$ from one another. If the system is subjected to load and the individual phases are equally loaded, the resultant neutral current will be zero but if there is presence of current harmonic in the system, then the triplen harmonic will sum up in the neutral link so much that the total current in the neutral surpass the individual current in each of the phases, to a factor of three.

This scenario may cause a situation of overload on the individual current and the neutral current. This can result in the overheating of the cables and the conductors may eventually get burnt (Kamenka, 2014).

ix. $\quad 2.4 .3$ Transformer

Transformers are devices that are widely known for the supply of electric power to facility loads which includes both linear and non-linear loads. Transformers are affected by harmonics in two specific ways; there are situations of additional losses within the transformer core and production of triplen harmonic current. The losses generated are a result of eddy current, resistive and magnetic losses in the core. These additional losses produce extra heat within the system which overtime reduces the operating life of the transformer insulation. For the purpose, especially in industrial applications with load that are non-linear, transformers cannot be put into use at full load because of the high level of harmonic distortion (Soni and Soni, 2014).

x. 2.4.4 Rotating Machine

Similar to the effect of harmonics on transformer, harmonics also result in additional power loss in motors and generators. The effect of the losses is such that there is high temperature build up within the devices as a result of the increase in the resistance of the system which is directly proportional to the rate of frequency increase. Hence, the harmonic current will lead to increased losses in the windings of the rotating machines. Another effect of harmonics on the rotating machine is the generation of higher vibrations inside the bearings and this can cause wear and tear within the system with an eventual earlier equipment weakness (Pinyol, 2015).

xi. 2.4.5 Circuit Breakers

Harmonic tend to cause an increase in current in power network and tend to create situations of incessant tripping in the system thereby disrupting operations. A residual current circuit breaker (RCCB) functions to sum up the current in the phase and neutral conductors and disconnects the power from load peradventure the summation does not fall within the rated limit. Harmonic situation disrupt this operation as the RCCB may not be able to add the high frequency component correctly leading to nuisance tripping that can result in shutdown in production process, loss of time and money (Ritesh Dash, Kunjan K. Mohapatra, Patrik R. Behera, 2014)

xii. 2.4.6 Power Factor Correction Capacitors (PFC)

The factors that lead to the dielectric breakdown of capacitors are temperature, voltage, current and overload in power. Situation of harmonics seriously have adverse effect on PFC capacitors such that an increase in the maximum value of voltage based on high harmonics creates additional dielectric stress, thereby causing partial discharge in the insulation and permanently damaging the capacitors. In most cases, issues that relate with capacitor performance or behavior are related to current. Also, the impedance with respect to the voltage harmonics decreases as the harmonic order increases because the relationship of the capacitive reactance to the frequency is not linear. Therefore, capacitors with voltage harmonics absorb higher current when compared with capacitors in a system without voltage harmonics. In essence, this implies that voltage harmonics in a system give rise to a situation of high current draw in capacitors and causes additional losses, quick aging of the insulation and the eventual damage of the PFC. This effects are aggravated if the harmonics are multiples of parallel or series resonance (Ciurro, 2009) 


\section{xiii. 2.4.7 Lights}

Incandescent lamps are generally non-linear loads and the useful life or age decreases with the level of harmonics present. Lamps with features comprising of ballast inductor or capacitor do present a resonance problem which causes harmonic distortion; thus if the lamp is operated at about $105 \%$ of its rated voltage, then its useful life falls by an approximate value of $47 \%$ (Suresh and Babu, 2015).

\subsection{Harmonics Mitigation Techniques}

In line with the sources and causes of harmonic distortion in power system, various elimination or mitigation techniques to trap or limit the occurrence of harmonics with different levels of effectiveness and efficiency are considered below.

1. Introduction of Active Harmonic Filter

The use of active harmonic filters in a power system introduces current component that can negate the effect of the harmonic contents in a non-linear load. Active harmonic filters come in different forms such as the series filter, shunt filter and hybrid filter but the most recent technology of harmonic filter available is the active filter. Active filtering technique is applicable in standalone applications or by installing the design in the input stage of a drive, UPS system or other power electronic devices. Considering all technologies in UPS application except from the use of Insulated Gate Bipolar Transistor (IGBT), the harmonics generated in these system are greater than the expected for most electrical system; hence the need for the input filter to reduce the harmonic content to a value which is less than 10 percent of total harmonic distortion of the input current. The addition of a transformer in the system will produce more inductance to the line which will additionally lower the harmonic distortion in the system (Steele, 2015).

Ideally, the active filter operates in such a manner that it observes the load current and eliminates the fundamental frequency current after which it will investigate remaining frequency content and the respective magnitude. Based on this analysis, the active filter will be able to pass in the required equal and opposite current to eliminate the different harmonics. The active filter has the capacity to cancel harmonics to the $50^{\text {th }}$ order and achieve a low level of current harmonic distortion to a value as low as $5 \%$. In order to use active harmonic filter in the power network, there is the need to take a measurement of the harmonics to be cancelled from the system after which an active filter that possesses the magnitude of harmonic current required to cancel the measured harmonic can be selected (Soni and Soni, 2014)

2. Use of K-Rated Transformers In Power Distribution Components

Generally, transformers are not manufactured and designed to operate under high harmonic content produced from the presence of non-linear load in the power network. The effect of this harmonics is such that it raises the magnetization core of the device leading to overheating and eventual sudden failure when in use.

The introduction of harmonics into power system brought about the development of the K-rated transformers. K-rated transformers are not design to eliminate harmonic, rather they are designed to handle the generated heat from the harmonic current. K- Factor values are within the range of 1 to 50 whereas a standard transformer that supplies linear load has a K-factor of 1. A high value of transformer's K-factor implies that the transformer can handle higher the degree of thermal energy generated from the harmonic current. The choice of transformer in terms of the K-factor is important in installation design and this is also dependent on the magnitude of harmonic content in the power network. Table 5 below shows the $\mathrm{K}$-factor ratings that are applicable for different percentage of harmonics (Eaton, 2017).

Table 5: K Factors Rating for Different Non-linear Load in Electrical System (Eaton, 2017)

\begin{tabular}{|l|c|}
\hline \multicolumn{1}{|c|}{ Non-linear Load } & K-rating \\
\hline Incidental electronic equipment representing $<5$ percent & $\mathrm{K} 1$ \\
\hline Harmonic-producing equipment representing $<35$ percent & $\mathrm{K} 4$ \\
\hline Harmonic-producing equipment representing $<50$ percent & $\mathrm{K} 7$ \\
\hline Harmonic-producing equipment representing $<75$ percent & $\mathrm{K} 13$ \\
\hline Harmonic-producing equipment representing $<100$ percent & $\mathrm{K} 20$ \\
\hline
\end{tabular}

3. Introduction of Line Reactors

In order to control the harmonic distortion produced in a Variable Speed Drive (VFD), there is the need to connect a series reactor with non-linear load at the input line of the drive (Ritesh Dash, Kunjan K. Mohapatra, Patrik R. Behera, 2014)

A line reactor, also called input AC reactors can simply be explained as an inductor that is connected in series between a load and the source. . It functions to limit the current the current harmonic characteristic thus reducing harmonic in the system (Rockwell and Wisconsin, 2016).

A line reactor also helps to mitigate the harmonics which the VFD creates back into the line. The rating of 
line reactor is in horse-power (hp) and the voltage rating of the drive is applicable for use. The figure below is an illustration of a VFD circuit of motors showing the AC and DC reactors. (Lenz, 2008)

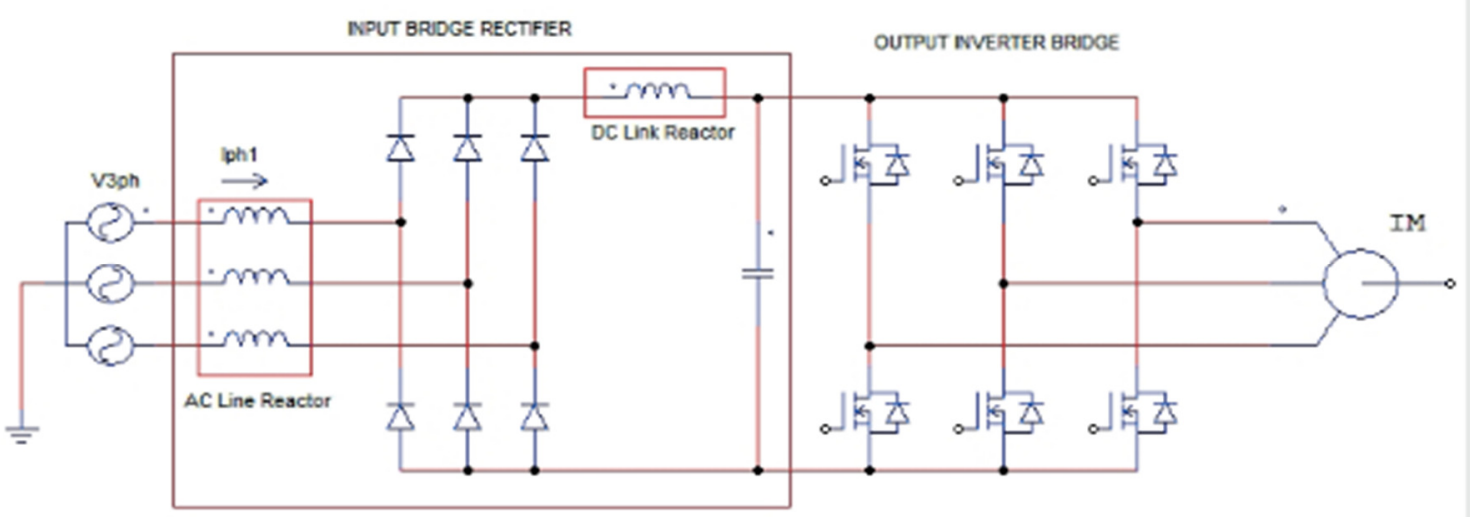

Figure 7: Circuit of a VFD of Motors Indicating the AC and DC Line reactors (Pinyol, 2015)

4. Over-sizing or Derating of the Installation

In reducing the effect of harmonics in a power system, the solution that is mostly implemented by technical personnel is to dimension for an oversized neutral conductor. However, where there is an existing installation, the solution is to reduce the capacity of the electrical distribution equipment experiencing the harmonic distortion. In modern times, the dimension of the neutral wire is always rated in the same size as the individual phase wires and may even be dimensioned (Soni and Soni, 2014).

\subsection{Recommended Harmonic Limit - IEEE Std. 519тм-2014}

Both the end users and power system operators should be responsible for the management of harmonics in power network. Harmonic limits recommendation span through the voltage and current parameters in a power network and the recommended values are on the premises that some level of voltage distortion are generally acceptable and it is the responsibilities of all parties involved to ensure that the actual voltage distortion is kept below the generally accepted limits. The basis of this recommended limit is that in the act of limiting the harmonic current in a system, and then voltage distortion can be within the recommended level (Committee, Power and Society, 2014).

The application of the recommended limit is applicable only at the point of common coupling and cannot be used in the applications of either individual equipment or locations in the industry or facilities. The various recommended limits for voltage and current harmonics are as shown in the following tables below.

Table 6: Recommended Voltage Distortion Limit (Committee, Power and Society, 2014)

\begin{tabular}{|c|c|c|}
\hline Bus voltage $V$ at PCC & $\begin{array}{c}\text { Individual } \\
\text { harmonic (\%) }\end{array}$ & $\begin{array}{c}\text { Total harmonic } \\
\text { distortion THD (\%) }\end{array}$ \\
\hline$V \leq 1.0 \mathrm{kV}$ & 5.0 & 8.0 \\
\hline $1 \mathrm{kV}<V \leq 69 \mathrm{kV}$ & 3.0 & 5.0 \\
\hline $69 \mathrm{kV}<V \leq 161 \mathrm{kV}$ & 1.5 & 2.5 \\
\hline $161 \mathrm{kV}<V$ & 1.0 & $1.5^{\mathrm{a}}$ \\
\hline
\end{tabular}

Table 7: Recommended Current Distortion Limits for Systems rated 120V through 69kV (Committee, Power and Society, 2014)

\begin{tabular}{|c|c|c|c|c|c|c|}
\hline \multicolumn{7}{|c|}{$\begin{array}{c}\text { Maximum harmonic current distortion } \\
\text { in percent of } \boldsymbol{L}_{\mathrm{L}}\end{array}$} \\
\hline \multicolumn{7}{|c|}{ Individual harmonic order (odd harmonics) $\mathbf{2 , \mathrm { b }}$} \\
\hline$I_{\mathrm{SC} /} / I_{\mathrm{L}}$ & $3 \leq h<11$ & $11 \leq h<17$ & $17 \leq h<23$ & $23 \leq h<35$ & $35 \leq h \leq 50$ & $\mathrm{TDD}$ \\
\hline$<20^{\mathrm{c}}$ & 4.0 & 2.0 & 1.5 & 0.6 & 0.3 & 5.0 \\
\hline $20<50$ & 7.0 & 3.5 & 2.5 & 1.0 & 0.5 & 8.0 \\
\hline $50<100$ & 10.0 & 4.5 & 4.0 & 1.5 & 0.7 & 12.0 \\
\hline $100<1000$ & 12.0 & 5.5 & 5.0 & 2.0 & 1.0 & 15.0 \\
\hline$>1000$ & 15.0 & 7.0 & 6.0 & 2.5 & 1.4 & 20.0 \\
\hline
\end{tabular}


Table 8: Recommended Current Distortion Limits for Systems rated 69kV through 161kV (Committee, Power and Society, 2014)

\begin{tabular}{|c|c|c|c|c|c|c|}
\hline \multicolumn{7}{|c|}{$\begin{array}{c}\text { Maximum harmonic current distortion } \\
\text { in percent of } \boldsymbol{I}_{\mathrm{L}}\end{array}$} \\
\hline \multicolumn{7}{|c|}{ Individual harmonic order (odd harmonics) $\mathrm{a}^{\mathrm{a}, \mathrm{b}}$} \\
\hline$I_{\mathrm{s} /} / I_{\mathrm{L}}$ & $3 \leq h<11$ & $11 \leq h<17$ & $17 \leq h<23$ & $23 \leq h<35$ & $35 \leq h \leq 50$ & $\mathrm{TDD}$ \\
\hline$<20^{\mathrm{c}}$ & 2.0 & 1.0 & 0.75 & 0.3 & 0.15 & 2.5 \\
\hline $20<50$ & 3.5 & 1.75 & 1.25 & 0.5 & 0.25 & 4.0 \\
\hline $50<100$ & 5.0 & 2.25 & 2.0 & 0.75 & 0.35 & 6.0 \\
\hline $100<1000$ & 6.0 & 2.75 & 2.5 & 1.0 & 0.5 & 7.5 \\
\hline$>1000$ & 7.5 & 3.5 & 3.0 & 1.25 & 0.7 & 10.0 \\
\hline
\end{tabular}

Table 9: Recommended Current Distortion Limits for Systems rated $>161 \mathrm{kV}$ (Committee, Power and Society, 2014)

\begin{tabular}{|c|c|c|c|c|c|c|}
\hline \multicolumn{7}{|c|}{$\begin{array}{c}\text { Maximum harmonic current distortion } \\
\text { in percent of } I_{\mathrm{L}}\end{array}$} \\
\hline \multicolumn{7}{|c|}{ Individual harmonic order (odd harmonics) $)^{\mathbf{2}, \mathbf{b}}$} \\
\hline$I_{\mathrm{s} /} / I_{\mathrm{L}}$ & $3 \leq h<11$ & $11 \leq h<17$ & $17 \leq h<23$ & $23 \leq h<35$ & $35 \leq h \leq 50$ & $\mathrm{TDD}$ \\
\hline$<25^{\mathrm{c}}$ & 1.0 & 0.5 & 0.38 & 0.15 & 0.1 & 1.5 \\
\hline $25<50$ & 2.0 & 1.0 & 0.75 & 0.3 & 0.15 & 2.5 \\
\hline$\geq 50$ & 3.0 & 1.5 & 1.15 & 0.45 & 0.22 & 3.75 \\
\hline
\end{tabular}

Based on the indices on Table 6 to 9 , the following are defined as:

$\mathrm{a}=$ Even harmonics are limited to $25 \%$ of the odd harmonic limits above.

$\mathrm{b}=$ Current distortions that result in a dc offset, e.g., half-wave converters, are not allowed.

$c=$ All power generation equipment is limited to these values of current distortion, regardless of actual $\mathrm{I}_{s c} / \mathrm{I}_{\mathrm{L}}$.

Where $\mathrm{I}_{\mathrm{sc}}$ relates to the peak short-circuit current at PCC, $\mathrm{I}_{\mathrm{L}}$ is defined as the peak demand load current (fundamental frequency component) at the PCC under normal load operating conditions.

2.6.1 Recommendations for Increasing Harmonic Current Limits

Following recommendations, the values as seen in Table 7, Table 8 and Table 9 can be increased by a multiplying factor when the user decides to reduce the magnitude of lower-order harmonics. The multipliers are given in Table 10 below and are put into use when steps are taken by the user to reduce the harmonic order shown in the first column of the table.

Table 10: Recommended Multipliers for Increasing the Harmonic Current Limit (Committee, Power and Society, 2014).

\begin{tabular}{|c|c|}
\hline $\begin{array}{c}\text { Harmonics orders limited to 25\% of values } \\
\text { given in Table 2, Table 3, and Table 4 }\end{array}$ & Multiplier \\
\hline 5,7 & 1.4 \\
\hline $5,7,11,13$ & 1.7 \\
\hline $5,7,11,13,17,19$ & 2.0 \\
\hline $5,7,11,13,17,19,23,25$ & 2.2 \\
\hline$\downarrow$ & $\downarrow$ \\
\hline
\end{tabular}

\section{Conclusion}

This paper presented research on harmonic distortion in the voltage and current waveform with respect to the existing level of harmonic distortion in the power system at the moment and the possible look at how harmonic will be portrayed in future.

Harmonics in power system is caused by the presence of non-linear load within the network. The different categories of equipment that give rise to harmonic distortion have numerous harmonic spectra and the peculiar harmonic spectra related to particular type of load can only be determined by having the requisite knowledge and experience in harmonics. Most of the harmonics generated from non-linear load are predominant in the electronics components which form the basis of modern technology. The demand for these types of equipment may result in serious problem in the future and the harmonic generated from these systems will significantly affect the power quality.

Harmonics in power system should not be treated with levity as they are of great concern in the power sector. Harmonics usually affects power infrastructure and the equipment therein and most times causes a down time in 
operations as people may think that the problem at that point is load related. Harmonics in power system lead to situation of over-current and over-heating leaving an impression of a possible situation of overload in the power system.

The problem of poor power quality relating to harmonics is not often noted by most practicing electrical engineers and consulting engineering firms and such problems if not critically analyzed would have impeded operations and establishment would have incurred a high cost in finding a solution; with an eventual damage to equipment. Good understanding of the causes, potential effects and means of mitigation can assist in the reduction of harmonic in the power system especially in the design stage of power infrastructure and the probabilities of undesired effect occurring can be reduced.

\section{Acknowledgement}

I am grateful to the school of Science and Engineering at Atlantic International University, Honolulu for giving me the required platform to be able to complete the research and analysis of this paper. I also acknowledge my team members at Powerex Limited for their understanding and cooperation while carrying out this research paper.

Profound gratitude goes to my wife and children; Ogunyemi Moyofoluwa, Oluwatofunmi and Oluwatoni for their support and understanding towards theh completion of this paper. You are greatly acknowledged.

\section{References}

Abdelaziz, A. Y., Mekhamer, S. F. and Ismael, S. M. (2012) 'Sources and Mitigation of Harmonics in Industrial Electrical Power Systems : State of the Art', (October).

Ciurro, N. (2009) 'Harmonics in Industrial Power Systems', (June).

Committee, D., Power, I. and Society, E. (2014) 'IEEE Recommended Practice and Requirements for Harmonic Control in Electric Power Systems IEEE Power and Energy Society', 2014.

Dash, R. et al. (2014) 'FUNDAMENTALS OF HARMONICS AND ITS EFFECT ON', 3(4), pp. 790-794.

Durdhavale, S. R. (2016) 'A Review of Harmonics Detection and Measurement in Power System', 143(10), pp. $8-11$.

Eaton (2017) 'Harmonics In Your Electrical System', What they are, how they can be harmful, and what to do about them, pp. 1-7. doi: 10.1164/ajrccm-conference.2017.A35.

Grady, P. M. (2012) 'Understanding Power System Harmonics', Chapter 1, (April).

IEEE Recommended Practices and Requirements for Harmonic Control in Electric Power Systems (1992) 'IEEE std 519-1992', Ieee, pp. 1-9. doi: 10.1109/PAPCON.2006.1673767.

Kamenka, A. (2014) 'Six tough topics about harmonic distortion and Power Quality indices in electric power systems A white paper of the Schaffner Group Written by Alexander Kamenka'.

Lenz (2008) 'Application Note- When to Use a Line or Load reactor', (July), pp. 1-3.

Marcuello, J. J. et al. (2011) 'A Review of Teaching Power System Harmonics', 1(2), pp. 1-5.

Ogheneovo Johnson, D. (2016) 'Issues of Power Quality in Electrical Systems', International Journal of Energy and Power Engineering, 5(4), p. 148. doi: 10.11648/j.ijepe.20160504.12.

Panda, G. et al. (2013) 'Novel schemes used for estimation of power system harmonics and their elimination in a three-phase distribution system', International Journal of Electrical Power and Energy Systems. Elsevier Ltd, 53, pp. 842-856. doi: 10.1016/j.ijepes.2013.05.037.

Pinyol, B. R. (2015) 'HARMONICS : CAUSES , EFFECTS AND MINIMIZATION', (August), pp. 1-32.

Ritesh Dash, Kunjan K. Mohapatra, Patrik R. Behera, M. R. S. (2014) 'A REVIEW ON POWER SYSTEM HARMONICS School of Electrical Engineering, Kiit University’, Indian Journal of Research, pp. 19911992.

Robert G.Ellis, P. E. (2011) 'POWER SYSTEM HARMONICS A Reference Guide to Causes ', pp. 1-3.

Rockwell, A. J. T. S. and Wisconsin, M. (2016) 'Line Reactors and AC Drives .'

Soni, M. K. and Soni, N. (2014) 'Review of Causes and Effect of Harmonics on Power System', 3(2), pp. 214220.

Steele, B. J. (2015) 'Mitigate damaging harmonics', (August), pp. 39-41.

Suresh, N. and Babu, R. S. R. (2015) 'Review on Harmonics and its Eliminating Strategies in Power System', 8(July). doi: 10.17485/ijst/2015/v8i13/56641. 